\title{
Data Envelopment Analysis with Lower Bound on Input to Measure Efficiency Performance of Department in Universitas Malikussaleh
}

\author{
Dahlan Abdullah ${ }^{1}$, Cut Ita Erliana ${ }^{2}$, Muhammad Fikry ${ }^{3}$ \\ ${ }^{I}$ Department of Informatics, Universitas Malikussaleh, Aceh Utara, Aceh, Indonesia \\ ${ }^{2}$ Department of Industrial Engineering, Universitas Malikussaleh, Aceh Utara, Aceh, Indonesia \\ ${ }^{3}$ Life Science and System Engineering Kyushu Institute of Technology, Japan \\ Idahlan@unimal.ac.id*
}

ARTICLE INFO

Article history:

Received: 09-04-2020

Revised : 20-05-2020

Accepted : 01-06-2020

Keywords:

Data Envelopment Analysis

Decision-Making Unit

Efficiency

Bounded Input

\begin{abstract}
DEA has become one of the most appropriate methods for comparing the various Decision-Making Units (DMU) associated with public services such as universities. There are two primary outputs that can be used to measure college performance, namely: the number of graduates and the number of publications. While the primary input of college efficiency measurement is the number of teaching staff and the number of students. The higher learning institution is Universitas Malikussaleh, located in Lhokseumawe, a city in the Aceh province of Indonesia. This paper develops a method to evaluate the efficiency of all departments in Universitas Malikussaleh using DEA with bounded input. The extreme dissimilarity between the weights often found in DEA applications. In this paper, we develop a new DEA model, which can be transformed into a particular case of the bi-level linear program to calculate the lower boundary of input from the pessimistic viewpoints based on the shortcomings of the existing approaches. In the case of having a single input, providing lower bounds for the input weights by imposing the conditions that it uses for the average input level of the DMU being assessed uses per unit of output. Accordingly, we present some essential differences inefficiency of those departments. Finally, we discuss the effort that should be made by these departments in order to become efficient.
\end{abstract}

Copyright $\odot 2017$ International Journal of Artificial Intelligence Research. All rights reserved.

\section{Introduction}

DEA has become one of the most appropriate methods for comparing the various DecisionMaking Units (DMUs) associated with public services such as universities [1]. Research conducted by [2] has two main outputs that can be used to measure college performance, namely: the number of graduates and the number of publications. On the other hand, research conducted by [3] that the primary input of college performance measurement is the number of teaching staff and the number of students.

$\mathrm{Wu}$ et al. [4] have examined that an astonishing number of outputs may arise in the form of deviations of the resulting output, based on the existing input parameters, when there is no limit to the output. This is seen in the study by [5] conducted a study on the efficiency of school performance in Greece by using a lower bound on the input and upper bound on the output, where an inefficient Decision-Making Unit (DMU) can occur. The primary constraint when establishing bounded on input and output based on the results of research conducted by [5] in the presence of missing value on input and output, and [5] corrected the missing value by using Fuzzy DEA. Abdullah et al. [6] have used Artificial Neural Network for optimizing DEA in order to predict the efficiency of the new patterns. 
In [7], users lower bounds input and upper bounds output to define the limits of efficiency measurement. Branda [8] suggests a DEA-oriented method of studying the relationship between input and output. Liu et al. [9] have examined Stochastic DEA (SDEA), which suggests an efficient way of obtaining upper and lower bounds of inputs and outputs based on several existing constraints.

Hassani and Malkhalifeh [10] proposed an interval model in evaluating the upper and lowered bound values for inputs and outputs and found that the DMU used for the determination of the lower bound is the worst DMU and the DMU used for upper bound determination is the best DMU. For every type of comparisons, they proposed two models to get the worst performance of each DMU as well as the best performance, and then achieved the upper and lower bound evaluation. Entani et al. [11] proposed a pessimistic DEA model for minimizing the efficiency of each DMU with the constraint that the maximum efficiency of all DMUs is one, and get an interval efficiency evaluation, which is further improved by [12] and Parchikolaei [13]. It was stated that interval DEA analyzes the performance of all DMUs more in detail than the traditional DEA. Additionally, Wang \& Yang [14] proposed the interval efficiency evaluation with the constraint that the efficiency of each DMU is not greater than one and not less than a lower bound, which is determined by a virtual anti-ideal DMU and is improved by [15]. The extreme dissimilarity between the weights often found in DEA applications [16]. Fang and Li have used lower bound in input for cost efficiency measure [17]. Briec and Dervaux [18] have used lower bound in input for Firm's Allocative Efficiency. Abdullah et al. [19] have used DEA with upper bound on the output to measure the efficiency performance of higher learning institutes. The research of Abdullah et al. [19] is output-oriented, and there must another research with input-oriented in the case of lower bound in the input.

Therefore in DEA, we should have a set of DMUs, multiple outputs, and multiple inputs. In the higher education system, DMU could be Departments to produce two outputs, such as the number of graduates $\left(\mathrm{y}_{1}\right)$ and the number of publications $\left(\mathrm{y}_{2}\right)$, form input, the number of teaching staff (x). This paper aims to evaluate the efficiency of all departments of Universitas Malikussaleh using DEA. We use DEA with the CCR model with input-oriented. In this case, the input variables are bounded. We show how to implement this bound in a DEA framework to Measure the Efficiency Performance of the Department in Universitas Malikussaleh.

The mathematical model of DEA proposed by CCR is fractional programming aimed to measure the efficiency of any DMU. The objective function of the model is to maximize a ratio of the sum of weighted output and the sum of weighted input with constraints of a similar ratio for every DMU, which should be at most one. The fractional programming model can be expressed as follows.

$$
\text { Maximize } \quad \alpha=\frac{\sum_{r=1}^{k} u_{r} y_{r 0}}{\sum_{s=1}^{l} v_{s} x_{s 0}}
$$

Subject to

$$
\begin{gathered}
\text { (1) } \frac{\sum_{r=1}^{k} u_{r} y_{r j}}{\sum_{s=1}^{l} v_{s} x_{s j}} ; \quad j=1, \ldots, n \\
u_{r}, v_{s} \geq 0 ; \quad r=1, \ldots, k ; \quad s=1, \ldots, l
\end{gathered}
$$

In the model, there is n number of DMUs with $\mathrm{k}$ number of outputs resulting from 1 number of inputs. $y_{r j}(>0)$ is the number of the output of the $j^{\text {th }} \mathrm{DMU}$, and $x_{s j}(>0)$ is the number of input of the $\mathrm{j}^{\text {th }}$ DMU. $u_{r}$ and $v_{s}$ are the variable weights to be determined after solving the model.

The (1) is in the form of fractional programming, and it would be computationally intractable, mainly when the number of DMUs is large. Therefore it is necessary to convert the model (1) into a linear programming problem, as proposed by [20], which can be written as follows (input-oriented). 


$$
\text { Minimize } \beta=\sum_{r=1}^{k} v_{s} x_{s j}
$$

Subject to

$$
\begin{gathered}
\sum_{s=1}^{l} u_{r} y_{r j}=1 \\
\sum_{r=1}^{k} u_{r} y_{r j}-\sum_{s=1}^{l} v_{s} x_{s j} \leq 0 ; \quad \forall j \\
u_{r}, v_{s} \geq 0 \quad \forall r, \forall s
\end{gathered}
$$

\section{Research Method}

The phase of the research process can be seen as in Fig. 1.

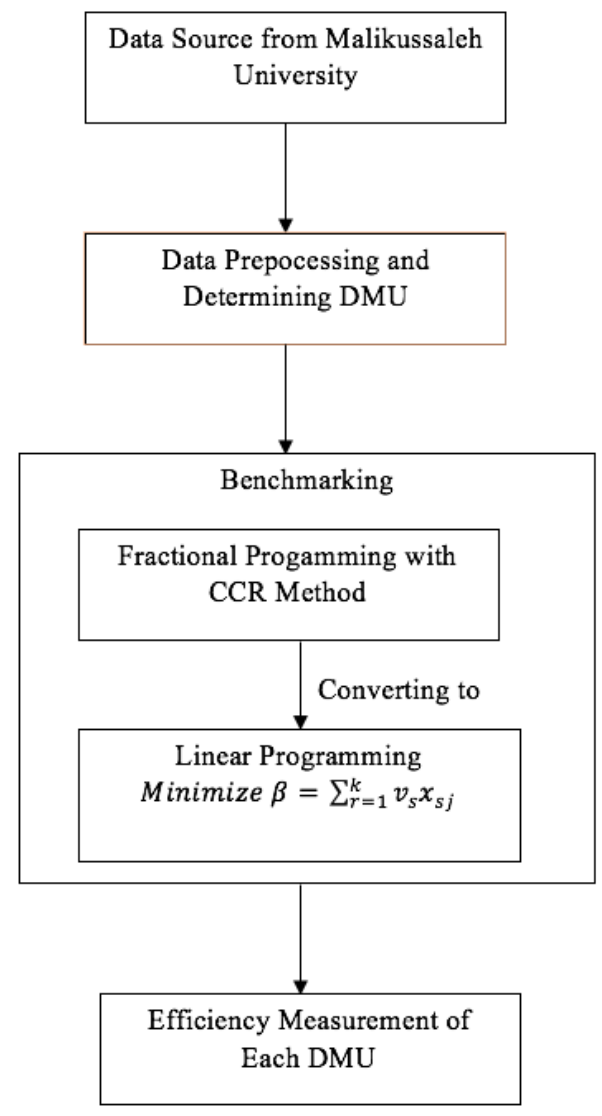

Fig. 1.Research Method

Fig. 1 shows that the data source from Universitas Malikussaleh will process in the data preprocessing step, and the process also determines the DMU for measure efficiency performance in Universitas Malikussaleh. In the next step, there is a benchmarking process that consists of steps for converting the fractional programming with CCR Method into Linear Programming with lower bound in the input. After this process, we will get the result of the efficiency measurement of each DMU.

\section{Results and Discussion}

Universitas Malikussaleh is a state university located at Lhokseumawe city of Aceh province, Indonesia. The name Malikussaleh comes from the name of the first king of the wellknown kingdom Samudra Pasai. This university has 30 Departments with around 20000 students.

The data of 19 Departments (DMU) with two outputs and two inputs are shown in Table1. There are 11 departments that are still new. Therefore they do not have graduates yet. As a consequence, these 11 departments are not included in Table 1 
Table 1. List of DMU with Input and Output Data

\begin{tabular}{|c|c|c|c|c|c|}
\hline \multirow[t]{2}{*}{ No } & \multirow[t]{2}{*}{ Dmu } & \multicolumn{2}{|c|}{ Input } & \multicolumn{2}{|c|}{ Output } \\
\hline & & $\begin{array}{c}\text { Number of } \\
\text { teaching staff }\end{array}$ & $\begin{array}{c}\text { Number of } \\
\text { students }\end{array}$ & $\begin{array}{c}\text { Number of } \\
\text { research }\end{array}$ & $\begin{array}{c}\text { Number of } \\
\text { graduates }\end{array}$ \\
\hline 1 & Information technology & 17 & 588 & 5 & 610 \\
\hline 2 & Civil engineering & 26 & 747 & 5 & 533 \\
\hline 3 & Architectural engineering & 15 & 396 & 5 & 195 \\
\hline 4 & Industrial engineering & 17 & 467 & 5 & 300 \\
\hline 5 & Chemical engineering & 25 & 348 & 5 & 252 \\
\hline 6 & Mechanical engineering & 23 & 499 & 5 & 224 \\
\hline 7 & Electrical engineering & 19 & 420 & 5 & 326 \\
\hline 8 & Agribusiness & 17 & 689 & 5 & 273 \\
\hline 9 & Agro-technology & 34 & 822 & 5 & 284 \\
\hline 10 & Aquaculture & 10 & 501 & 5 & 204 \\
\hline 11 & Communication science & 11 & 719 & 5 & 273 \\
\hline 12 & Political science & 11 & 262 & 5 & 183 \\
\hline 13 & Sociology & 13 & 487 & 5 & 204 \\
\hline 14 & Anthropology & 9 & 173 & 5 & 116 \\
\hline 15 & Jurisprudence & 50 & 1096 & 10 & 467 \\
\hline 16 & Medicine & 30 & 278 & 4 & 257 \\
\hline 17 & Management & 48 & 1265 & 5 & 1302 \\
\hline 18 & Economic development & 11 & 853 & 5 & 290 \\
\hline 19 & Accounting & 23 & 1127 & 5 & 417 \\
\hline
\end{tabular}

Using the model (3), we can find the score of efficiency. For example, for DMU1 (Department of Information Technology), the linear programming model can be written as follows.

Minimize $17 \mathrm{~V} 1+588 \mathrm{~V} 2$

Subject to

$$
\begin{aligned}
& 610 \mathrm{U} 1+5 \mathrm{U} 2=1 \\
& 610 \mathrm{U} 1+5 \mathrm{U} 2-17 \mathrm{~V} 1-588 \mathrm{~V} 2<=0 \\
& 533 \mathrm{U} 1+5 \mathrm{U} 2-26 \mathrm{~V} 1-747 \mathrm{~V} 2<=0 \\
& 195 \mathrm{U} 1+5 \mathrm{U} 2-15 \mathrm{v} 1-396 \mathrm{~V} 2<=0 \\
& 300 \mathrm{U} 1+5 \mathrm{U} 2-17 \mathrm{~V} 1-467 \mathrm{~V} 2<=0 \\
& 252 \mathrm{U} 1+5 \mathrm{U} 2-25 \mathrm{~V} 1-348 \mathrm{~V} 2<=0 \\
& 224 \mathrm{U} 1+5 \mathrm{u} 2-23 \mathrm{~V} 1-499 \mathrm{~V} 2<=0 \\
& 326 \mathrm{U} 1+5 \mathrm{U} 2-19 \mathrm{~V} 1-420 \mathrm{~V} 2<=0 \\
& 273 \mathrm{U} 1+5 \mathrm{U} 2-17 \mathrm{~V} 1-689 \mathrm{~V} 2<=0 \\
& 284 \mathrm{U} 1+5 \mathrm{U} 2-34 \mathrm{~V} 1-822 \mathrm{~V} 2<=0 \\
& 204 \mathrm{U} 1+5 \mathrm{U} 2-10 \mathrm{~V} 1-501 \mathrm{~V} 2<=0 \\
& 273 \mathrm{U} 1+5 \mathrm{U} 2-11 \mathrm{~V} 1-719 \mathrm{~V} 2<=0 \\
& 183 \mathrm{U} 1+5 \mathrm{U} 2-11 \mathrm{~V} 1-262 \mathrm{~V} 2<=0 \\
& 204 \mathrm{U} 1+5 \mathrm{U} 2-13 \mathrm{~V} 1-487 \mathrm{~V} 2<=0 \\
& 116 \mathrm{U} 1+5 \mathrm{U} 2-9 \mathrm{~V} 1-173 \mathrm{~V} 2<=0 \\
& 467 \mathrm{U} 1+5 \mathrm{U} 2-50 \mathrm{~V} 1-1096 \mathrm{~V} 2<=0 \\
& 257 \mathrm{U} 1+5 \mathrm{U} 2-30 \mathrm{~V} 1-278 \mathrm{~V} 2<=0 \\
& 1302 \mathrm{U} 1+5 \mathrm{U} 2-48 \mathrm{~V} 1-1265 \mathrm{~V} 2<=0 \\
& 290 \mathrm{U} 1+5 \mathrm{U} 2-11 \mathrm{~V} 1-852 \mathrm{~V} 2<=0 \\
& 417 \mathrm{U} 1+5 \mathrm{U} 2-23 \mathrm{~V} 1-1127 \mathrm{~V} 2<=0 \\
& \mathrm{U} 1, \mathrm{U} 2, \mathrm{~V} 1, \mathrm{~V} 2>=0
\end{aligned}
$$


The result from processing using Model (3) showed in Table 2.

Table 2. Result of Efficiencies for Each DMU using Lower Bound in Input

\begin{tabular}{ccc}
\hline No & DMU & DEA Score \\
\hline $\mathbf{1}$ & information technology & 1.0 \\
\hline $\mathbf{2}$ & civil engineering & 1.43 \\
\hline $\mathbf{3}$ & architectural engineering & 1.47 \\
\hline $\mathbf{4}$ & industrial engineering & 1.42 \\
\hline $\mathbf{5}$ & chemical engineering & 1.24 \\
\hline $\mathbf{6}$ & mechanical engineering & 1.89 \\
\hline $\mathbf{7}$ & electrical engineering & 1.21 \\
\hline $\mathbf{8}$ & agribusiness & 1.5 \\
\hline $\mathbf{9}$ & agro-technology & 2.62 \\
\hline $\mathbf{1 0}$ & aquaculture & 1 \\
\hline $\mathbf{1 1}$ & communication science & 1 \\
\hline $\mathbf{1 2}$ & political science & 1 \\
\hline $\mathbf{1 3}$ & sociology & 1.27 \\
\hline $\mathbf{1 4}$ & anthropology & 1 \\
\hline $\mathbf{1 5}$ & jurisprudence & 2.02 \\
\hline $\mathbf{1 6}$ & medicine & 1.0391 \\
\hline $\mathbf{1 7}$ & management & 1 \\
\hline $\mathbf{1 8}$ & economic development & 1 \\
\hline $\mathbf{1 9}$ & accounting & 1.7 \\
\hline
\end{tabular}

From the Table 2, DMU 1, 10, 11, 12, 14, 17, and 18 are efficient. Another DMU is inefficient. For inefficient DMU, we can use the Slack-Based Measure in determining the input surplus. The slack value of each DMU can be seen in Table 3.

Table 3. Slack Value for The Inefficient DMU

\begin{tabular}{ccc}
\hline No & DMU & Slack Value \\
\hline $\mathbf{1}$ & civil engineering & 0.48 \\
\hline $\mathbf{2}$ & architectural engineering & 0.47 \\
\hline $\mathbf{3}$ & industrial engineering & 0.42 \\
\hline $\mathbf{4}$ & chemical engineering & 0.45 \\
\hline $\mathbf{5}$ & mechanical engineering & 0.67 \\
\hline $\mathbf{6}$ & electrical engineering & 0.38 \\
\hline $\mathbf{7}$ & agribusiness & 0.67 \\
\hline $\mathbf{8}$ & agro-technology & 0.82 \\
\hline $\mathbf{9}$ & sociology & 0.68 \\
\hline $\mathbf{1 0}$ & jurisprudence & 0.78 \\
\hline $\mathbf{1 1}$ & medicine & 0.58 \\
\hline $\mathbf{1 2}$ & accounting & 0.7 \\
\hline
\end{tabular}

We will deal with $n$ DMUs (Decision Making Units) with the input and output matrices $X=\left(\chi_{i j}\right) \in R^{\operatorname{mxn}}$ and $Y=\left(y_{i j}\right) \in R^{s x n}$, respectively. We assume that the data set is positive, i.e., $X>0$ and $Y>0$. The production possibility set $P$ is defined as [21].

$$
P=\{(x, y) \mid x \geq X \lambda, y \leq Y \lambda, \lambda \geq 0\}
$$

We consider an expression for describing a certain DMU $\left(x_{0}, y_{0}\right)$ as

$$
\begin{gathered}
x_{0}=X \lambda+S^{-} \\
y_{0}=Y \lambda-s^{+}
\end{gathered}
$$

From the expression in (5) and (6), we can reduce the number of input; in this case, the number of students can be reduced. For example, in DMU 19 from Table 2. DMU Accounting had many students in 1127, and the slack value is 0.7. So, the student of DMU Accounting must be reduced to:

$$
V_{2}=1127-1127 * 0.7=338
$$


After we reduce the number of student in DMU Accounting become 338. The DEA Score becomes efficient.

\section{Conclusion}

First, this research can be seen that there is a bounded input strategy that can determine well the amount of input needed to produce an output so that no excess input. In contrast, the resulting output is not maximal; from the college side, this can be burdensome from the side of teaching. Second, for less efficient departments or DMUs, it can reduce the number of students based on the slack values gained for each DMU. Third, based on reducing the number of students according to slack value, can make the existing DMU efficient.

\section{References}

[1] T. Rosenmayer, "Using Data Envelopment Analysis: A Case of Universities," Rev. Econ. Perspect., vol. 14, no. 1, Jan. 2014.

[2] N. Hussein, S. Omar, F. Noordin, and N. A. Ishak, "Learning Organization Culture, Organizational Performance and Organizational Innovativeness in a Public Institution of Higher Education in Malaysia: A Preliminary Study," Procedia Econ. Finance, vol. 37, pp. 512-519, 2016.

[3] Etzkowitz, "University-Industry-Government Interaction: The Triple Helix Model of Innovation," Asia Pac. Tech Monit., vol. 24, no. 1, pp. 14-23, 2007.

[4] J. Wu, P. Yin, J. Sun, J. Chu, and L. Liang, "Evaluating the environmental efficiency of a two-stage system with undesired outputs by a DEA approach: An interest preference perspective," Eur. J. Oper. Res., vol. 254, no. 3, pp. 1047-1062, Nov. 2016.

[5] Y. G. Smirlis, E. K. Maragos, and D. K. Despotis, "Data envelopment analysis with missing values: An interval DEA approach," Appl. Math. Comput., vol. 177, no. 1, pp. 1-10, Jun. 2006.

[6] D. Abdullah, Tulus, S. Suwilo, S. Effendi, and Hartono, "DEA Optimization with Neural Network in Benchmarking Process," IOP Conf. Ser. Mater. Sci. Eng., vol. 288, p. 012041, Jan. 2018.

[7] W. W. Cooper, J. T. Pastor, F. Borras, J. Aparicio, and D. Pastor, "BAM: a bounded adjusted measure of efficiency for use with bounded additive models," J. Product. Anal., vol. 35, no. 2, pp. 85-94, Apr. 2011.

[8] M. Branda, "Reformulations of input-output oriented DEA tests with diversification," Oper. Res. Lett., vol. 41, no. 5, pp. 516-520, Sep. 2013.

[9] W. Liu, Y.-M. Wang, and S. Lyu, "The upper and lower bound evaluation based on the quantile efficiency in stochastic data envelopment analysis," Expert Syst. Appl., vol. 85, pp. 14-24, Nov. 2017.

[10] T. Hassani and M. Rostamy-Malkhalifeh, "Efficiency of decision making units in network DEA using interval data," p. 8, 2016.

[11]T. Entani, Y. Maeda, and H. Tanaka, "Dual models of interval DEA and its extension to interval data," Eur. J. Oper. Res., vol. 136, no. 1, pp. 32-45, Jan. 2002.

[12] T. Entani and H. Tanaka, "Improvement of efficiency intervals based on DEA by adjusting inputs and outputs," Eur. J. Oper. Res., vol. 172, no. 3, pp. 1004-1017, Aug. 2006.

[13] B. Rahmani Parchikolaei, "The lower limit of interval efficiency in Data Envelopment Analysis," Data Envel. Anal. Decis. Sci., vol. 2015, no. 1, pp. 58-66, 2015.

[14] Y.-M. Wang and J.-B. Yang, "Measuring the performances of decision-making units using interval efficiencies," J. Comput. Appl. Math., vol. 198, no. 1, pp. 253-267, Jan. 2007.

[15]H. Azizi and Y.-M. Wang, "Improved DEA models for measuring interval efficiencies of decisionmaking units," Measurement, vol. 46, no. 3, pp. 1325-1332, Apr. 2013.

[16] N. Ramón, J. L. Ruiz, and I. Sirvent, "A multiplier bound approach to assess relative efficiency in DEA without slacks,” Eur. J. Oper. Res., vol. 203, no. 1, pp. 261-269, May 2010.

[17] L. Fang and H. Li, "Lower bound of cost efficiency measure in DEA with incomplete price information," J. Product. Anal., vol. 40, no. 2, pp. 219-226, Oct. 2013.

[18] W. Briec, B. Dervaux, H. Leleu, W. Briec, B. Dervaux, and H. Leleu, A DEA Estimation of a Lower Bound for Firms' Allocative Efficiency Without Information on Price Data. 2007.

[19]D. Abdullah, T. Tulus, S. Suwilo, S. Efendi, M. Zarlis, and H. Mawengkang, "A Research Framework for Data Envelopment Analysis with Upper Bound on Output to Measure Efficiency Performance of Higher Learning Institution in Aceh Province," Int. J. Adv. Sci. Eng. Inf. Technol., vol. 8, no. 2, 2018. 
[20] A. Charnes, W. W. Cooper, and E. Rhodes, "Measuring the efficiency of decision-making units," Eur. J. Oper. Res., vol. 3, no. 4, p. 339, Jul. 1979.

[21] K. Tone, "A slacks-based measure of e ciency in data envelopment analysis," Eur. J. Oper. Res., p. 12, 2001 